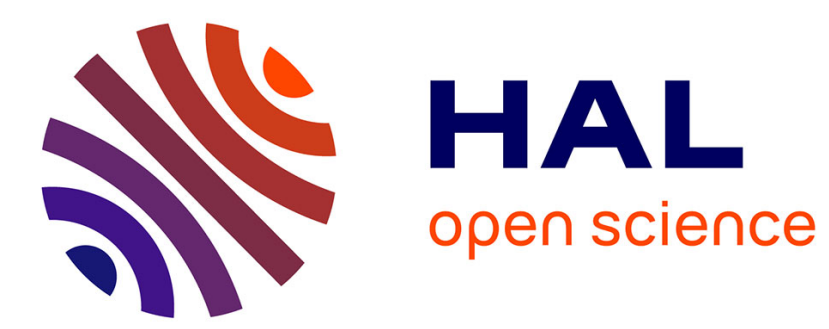

\title{
PLASTIC DEFORMATION OF A Cu-1.92 w/o Fe ALLOY
}

F. Hornstein, M. Ron

\section{To cite this version:}

F. Hornstein, M. Ron. PLASTIC DEFORMATION OF A Cu-1.92 w/o Fe ALLOY. Journal de Physique Colloques, 1974, 35 (C6), pp.C6-497-C6-500. 10.1051/jphyscol:19746103 . jpa-00215714

\section{HAL Id: jpa-00215714 https://hal.science/jpa-00215714}

Submitted on 1 Jan 1974

HAL is a multi-disciplinary open access archive for the deposit and dissemination of scientific research documents, whether they are published or not. The documents may come from teaching and research institutions in France or abroad, or from public or private research centers.
L'archive ouverte pluridisciplinaire HAL, est destinée au dépôt et à la diffusion de documents scientifiques de niveau recherche, publiés ou non, émanant des établissements d'enseignement et de recherche français ou étrangers, des laboratoires publics ou privés. 


\title{
PLASTIC DEFORMATION OF A Cu-1.92 w/o Fe ALLOY
}

\author{
F. HORNSTEIN and M. RON
}

\author{
Department of Materials Engineering (*), \\ Technion, Israel Institute of Technology, Haifa, Israel
}

\begin{abstract}
Résumé. - Diverses configurations atomiques et phases métastables existant dans un alliage $\mathrm{Cu}-1,92 \mathrm{p} / \mathrm{o} \mathrm{Fe}$ ont été étudiées par effet Mössbauer sur ${ }^{57} \mathrm{Fe}$. On a observé des changements des quantités relatives et des structures de ces espèces à la suite de traitements thermiques et de déformations plastiques. On a trouvé que dans un échantillon trempé rapidement à partir de $1050^{\circ} \mathrm{C}$, la distribution des atomes de fer dans une solution solide s'écarte de la distribution statistique. Une déformation plastique homogénéise la solution solide, probablement par rupture de petits agrégats métastables induite par le déplacement de dislocations.

L'abondance et la taille des agrégats $\gamma_{2}^{(n)}$ d'atomes de fer ont été étudiées via l'interaction quadrupolaire. On considère la contribution à l'interaction quadrupolaire de la plus proche et de la seconde coordination d'un atome de fer et on la relie à la taille des agrégats. Les modifications des paramètres Mössbauer de la raie $\gamma_{0}$ sont interprétées comme inđiquant un relâchement des tensions de compression imposées à un atome de fer en site de substitution dans le cuivre.
\end{abstract}

\begin{abstract}
A number of atomic configurations and metastable phases existing in a $\mathrm{Cu}-1.92$ w/o Fe alloy were studied by the Mössbauer effect in $\mathrm{Fe}^{57}$. Changes occurring in the relative amounts and structure of these species as a result of thermal treatment and plastic deformation, were observed. In a sample quenched rapidly from $1050^{\circ} \mathrm{C}$, the distribution of $\mathrm{Fe}$-atoms in solid solution was found to deviate from randomness. Plastic deformation randomises the solid solution-presumably breaking-up small metastable clusters by moving dislocations.

The abundance and size of the $\gamma_{2}^{(n)}$-clusters of Fe-atoms were studied via the quadrupole interaction. The contribution to the quadrupole splitting of the nearest and next nearest coordination of an Fe-atom is considered and related to the size of the clusters. The changes in the Mössbauer parameters of the $\gamma_{0}$-line are interpreted as indicating a relief in the compressive stresses imposed upon an $\mathrm{Fe}$ atom at a substitutional lattice site in $\mathrm{Cu}$.
\end{abstract}

1. Introduction. - After the alloy $\mathrm{Cu}-1.92 \mathrm{w} / \mathrm{o} \mathrm{Fe}$ is quenched from the solid solution treatment temperature of $1050^{\circ} \mathrm{C}$, a number of metastable iron rich phases and atomic configurations are known to appear upon aging before the stable $\alpha$-Fe precipitate forms $[1,2,3,4]$ :

a) A supersaturated solution of $\mathrm{Fe}$ in $\mathrm{Cu}$, designated $\gamma_{0}$ and represented in the Mössbauer spectrum by a line located at $\sim 0.20 \mathrm{~mm} / \mathrm{s}$, relative to $\alpha$-iron [2]

b) Coherent precipitates of f. c. c.-iron, $\gamma$-Fe designated $\gamma_{2}$ and represented in the Mössbauer spectrum as a single line located at $\sim-0.10 \mathrm{~mm} / \mathrm{s}$, relative to $\alpha$-Fe [2].

c) Clusters of $n$-Fe atoms designated $\gamma_{2}^{(n)}, n=1,2, \ldots$ and represented by a doublet in the central part of the Mössbauer spectrum [3].

The transformation $\gamma \rightarrow \alpha$ is known to be caused by overaging, or by plastic deformation if large $\gamma$-iron

$\left.{ }^{*}\right)$ This research was sponsored by The National Council for Research and Development of Israel and ELSCINT Limited, Haifa. precipitates are present [1]. This phase reveals a magnetically split, six-line spectrum [2].

In the present study the Mössbauer effect is used to follow the changes occurring in the relative amounts, coordination and stresses of the metastable species $\gamma_{2}^{(n)}$ and $\gamma_{0}$, as a result of cold-work and/or aging.

2. Experimental procedure. - High purity $\mathrm{Cu}$ and Fe enriched in $\mathrm{Fe}^{57}$ were melted under a reducing atmosphere. Atomic absorption analysis indicated a concentration of $1.92 \mathrm{w} / \mathrm{o}$ iron. The specimen was rolled into a foil $40 \mu \mathrm{m}$ thick and then reheated for homogenization at $1050^{\circ} \mathrm{C}$ for $12 \mathrm{~h}$ under the same protective atmosphere. The specimen was then quenched rapidly in a mixture of ice and water without coming in touch with air. Subsequently, the specimen was rolled to various degrees of reduction and Mössbauer spectra of the specimen were taken at each stage.

The spectra were taken with the aid of an Elscint type computerized Mössbauer spectrometer [5] and a $25 \mathrm{mCi}$ single line source of $\mathrm{Co}^{57}$ in $\mathrm{Pd}$ matrix.

The Mössbauer spectrometer was calibrated relative 
to the 4 inner lines of $\alpha-\mathrm{Fe}$; the width at half maximum of the inner lines was $0.23 \mathrm{~mm} . \mathrm{s}^{-1}$.

The Mössbauer spectra were analyzed as a superposition of a single line related to $\gamma_{0}$, a single line for $\gamma_{1}$ and a doublet for $\gamma_{2}^{(n)}$.

Several distribution of lines have been tried for obtaining fits for the $\gamma_{2}^{(n)}$ lines ; a Gaussian distribution of doublets has been used for an analysis of the $\gamma^{(n)}$. phase by Window [4] while Campbell et al. [6] have used an increasing number of symmetric doublets which were fitted until no significant improvement in the quality of the fit, was observed. They found that two doublets give satisfactory fits for concentrations below $\sim 1.9 \%$ Fe.

In this study a superposition of two symmetric doublets was used for obtaining a fit for the $\gamma_{2}^{(n)}$-phase. In addition, one doublet of Lorenzian lines was used for obtaining mean quadrupole splitting and isomer shift for the $\gamma_{2}^{(n)}$-phase, as described in the following section.

3. Results. - For the purpose of differentiating the contributions of clusters having different $n-s$ and different spatial coordination the portion of the spectrum related to $\gamma_{2}^{(n)}$ has to be considered as a superposition of a number of doublets $[4,6]$. A superposition of two symmetric doublets with lines of Lorenzian shape was found to provide a fit for the $\gamma_{2}^{(n)}$-phase, which was not improved by further increase of the number of doublets.

The doublet with the larger splitting was related to clusters of $\gamma_{2}^{(1)}$-consisting mainly of Fe-atoms with one Fe-nearest neighbor (n.n.); the doublet with the smaller splitting was related to clusters of $\gamma_{2}^{(2)}$-consisting of Fe-atoms"with two (and more) Fe- $n . n$.

The above classification is an idealization, neglecting factors such as next nearest Fe-neighbors, vacancies and other imperfections and surface (interface) Featoms all of which introduce a distribution and overlap of hyperfine parameters.

The relative amount (atomic fraction) of $\gamma_{0}$-Fe atoms without Fe-n. n. and Fe-atoms of the two types $\gamma_{2}^{(1)}$ and $\gamma_{2}^{(2)}$, were traced in figure 1 as a function of coldwork. The $f$-factor of the $\gamma_{2}^{(n)}$-phase was found to be 0.73 - a value very close to that of the $\gamma_{0}$-phase $[7,8]$.

In the as quenched state the fraction of $\gamma_{2}^{(1)}$ and $\gamma_{2}^{(2)}$ exceed the fraction calculated for a random distribution [9] by a factor of $\sim 2$ and $\sim 14$, respectively. The fact that the fraction of $\gamma_{0}$ increases with reduction indicates that cold work randomizes the alloy.

The mean isomer shift and quadrupole splitting, I. S., Q. S., were obtained by fitting two Lorezian lines of equal integrated intensity, and of unrestricted line width.

As a matter of fact, the left hand peak of the doublet changes very little in position and line width. The quality of this fit was almost as good as that obtained with two doublets.

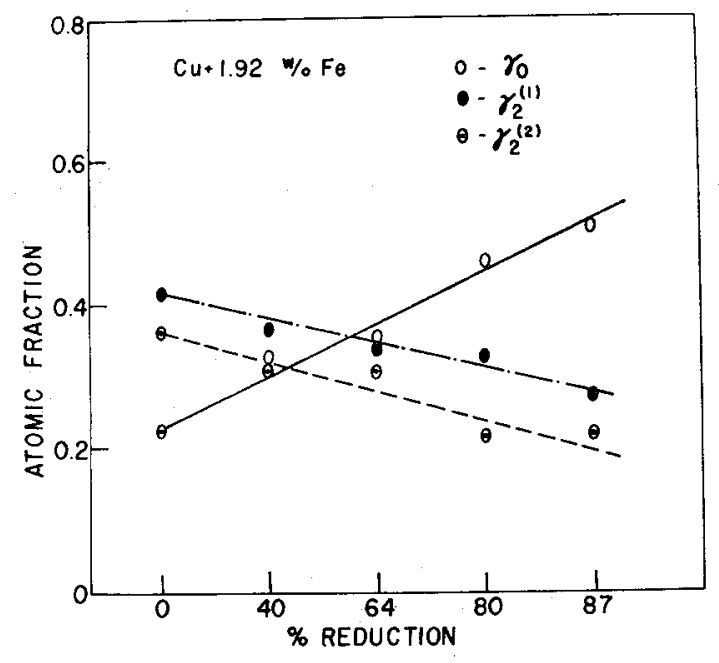

FIG. 1. - Atomic fraction of $\gamma_{0}, \gamma_{2}^{(1)}$ and $\gamma_{2}^{(2)}$ as a function of cold-work.

In figure 2 the mean $\mathrm{Q}$.S. and I. S. of the $\gamma_{2}^{(n)}$-phase are plotted against cold-work. The Q.S. is seen to increase markedly with the degree of reduction. Room temperature Mössbauer spectra for a sample as quenched, rolled and aged at $350^{\circ} \mathrm{C}$ were shown in figure 3.

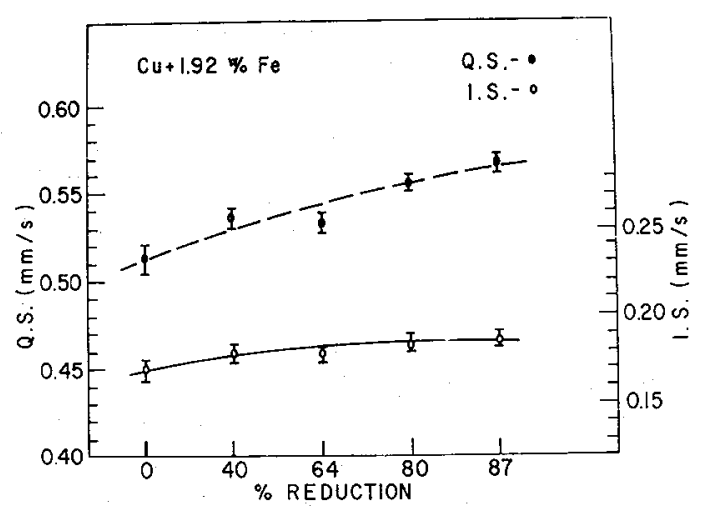

FIG. 2. - The mean quadrupole splitting - and mean isomer shift - of the $\gamma_{2}^{(n)}$ cluster as a function of cold-work.

The change in the shape of the spectra reflects the changes in the relative amounts and the Mössbauer parameters of the $\gamma_{2}^{(n)}$ and $\gamma_{0}$-phases.

The mean quadrupole splitting $\mathrm{Q}$.S. for the $\gamma_{2}^{(n)}$ phase is shown in figure 4 as a function of aging time. It is clearly seen that the $\mathrm{Q}$. S. decreases with both the aging temperature and time.

A shift of $0.02 \mathrm{~mm} / \mathrm{s}$ in the position of the $\gamma_{0}$ line and a broadening of almost twice the shift, was observed [9] (not shown here) for a sample cold-worked to $87 \%$ reduction. The positive sign of this change, $\Delta$ (I. S.) $\gamma_{0}>0$, implies a decrease in $\left|\psi_{\mathrm{s}}(0)\right|^{2}$ - the s-electron density on the $\mathrm{Fe}^{57}$ nucleus. This corresponds to a relief in compressional stress imposed on an Fe atom substituted in a copper crystal. 


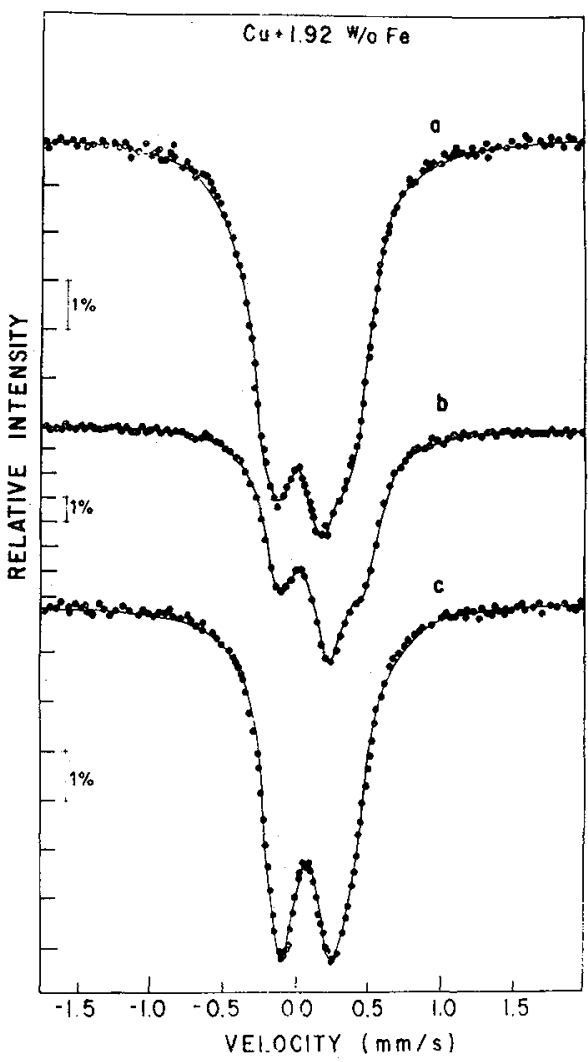

FIG. 3. - Room temperature Mössbauer spectra for $\mathrm{Cu}-1.92$ w/o Fe alloy : $a$ ) as quenched ; $b$ ) quenched and rolled to $87 \%$ reduction;c) quenched and aged at $300{ }^{\circ} \mathrm{C}$ for 4 hours.

4. Interpretation and discussion. - It has been found by N.M. R. measurements on copper that substitutional impurity atoms of many elements create an e. f. g. in the order of $1 \AA^{-1}$ at the nearest neighbours site of the impurity $[10,11]$. It has also been established that in copper alloys, the main contribution to the e. $f$. $g$. is due to the scattering of the conduction electrons and that the effect of strain is negligible [12].

A single $\mathrm{Fe}^{57}$ impurity atom in a copper matrix indicates by Mössbauer measurements no quadrupole interaction, in spite of the e.f.g. existing on its 12 nearest copper neighbors.

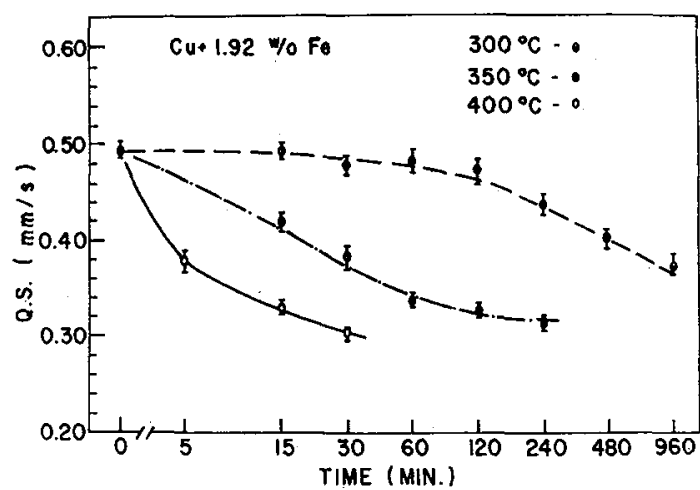

Frg. 4. - The mean quadrupole splitting of the $\gamma_{2}^{(n)}$-clusters as a function of aging time for three aging temperatures:

$\odot$-aged at $300^{\circ} \mathrm{C} ; 0$-aged at $350^{\circ} \mathrm{C} ; 0$-aged at $400^{\circ} \mathrm{C}$.

If then one of the Cu-n. $n$. is substituted for, by an Fe-atom, an appreciable Q.S. will appear in the Mössbauer spectrum due to the reduced symmetry of each Fe-atom (in the pair).

In fact the Q. S. obtained for small clusters of Fe in $\mathrm{Cu}(0.3 \sim 0.55 \mathrm{~mm} / \mathrm{s})$ is of the same order of magnitude as that if calculated by using the value of the e. f. $g$. obtained from N. M. R. measurements $(\sim 0.3 \mathrm{~mm} / \mathrm{s})$.

The magnitude of the Q. S. for clusters of Fe-atoms in a copper matrix depends on $n$-the number of Featoms in the cluster and on their spatial coordination. If only $n . n$. interactions are considered, a qualitative estimate can be made by using the following assumptions :

a) The clusters consist of Fe-atoms at f. c. c. sites in the copper matix.

b) The Q. S. decreases generally with the symmetry of the cluster.

c) For a given $n$ the closest packed configuration is the stable one; $i$. e. the one possessing the largest number of $n . n$.-bonds per added atom.

This leads to the classification described in table I.

Further increase of $n$-will produce configurations consisting of those listed above, however the effect of next $n$. $n$. will increase.

\section{TABLE I}

Spatial coordination of the $\gamma_{2}^{(n)}$ clusters

\begin{tabular}{|c|c|c|c|c|c|}
\hline $\begin{array}{l}\text { No. of } \\
\text { atoms }\end{array}$ & Configuration & Atomic Positions & $\begin{array}{l}\text { Symmetry } \\
\text { group }\end{array}$ & $\begin{array}{l}\text { Quadrupole } \\
\text { (Fe nn efg) }\end{array}$ & $\begin{array}{l}\text { No. of } \\
\mathrm{Fe} n \mathrm{n}\end{array}$ \\
\hline - & - & - & - & - & - \\
\hline 1 & single atoms & & & nil & 0 \\
\hline 2 & line & $(000), \frac{1}{2}(110)$ & $\mathrm{mmm}$ & maximal & 1 \\
\hline 3 & triangle & $(000), \frac{1}{2}(110), \frac{1}{2}(101)$ & $3 \mathrm{~m}$ & large & 2 \\
\hline 4 & tetrahedron & $(000), \frac{1}{2}(110), \frac{1}{2}(101), \frac{1}{2}(011)$ & $32 \mathrm{~m}$ & nil & 3 \\
\hline 5 & & $(000), \frac{1}{2}(110), \frac{1}{2}(101), \frac{1}{2}(011),(001)$ & $\mathrm{m}$ & $\begin{array}{c}\text { large } \\
\text { (for } 1 \text { atom of } 5 \text { ) }\end{array}$ & 2,3 \\
\hline 6 & octahedron & $(000),(001), \frac{1}{2}(011), \frac{1}{2}(011), \frac{1}{2}(101), \frac{1}{2}(101)$ & 432 & nil & 4 \\
\hline
\end{tabular}


This will generally cause a small Q. S. and produce a distribution in the Q. S.

If large $f$. c. c. clusters exist, an Fe-atom added to a surface (interface) will create a tetrahedral or octahedral configuration, which causes no quadrupole effect if only $n . n$. interaction is considered. The next $n$. n. (and higher) interactions create a quadrupole smaller in magnitude than the one created by the $n . n$. interaction.

The increase in the mean quadrupole interaction Q.S. of the $\gamma_{2}^{(n)}$ with the degree of reduction (shown in Fig. 2) can be interpreted as increasing the contribution of the larger Q. S. related to the smallest $\gamma_{2}^{(1)}$ clusters. Thus severe cold-work breaks up the larger clusters, increasing thereby the relative amount of $\gamma_{0}$ and $\gamma_{2}^{(1)}$.

From the results (Fig. 4) it is seen that the Q.S. of the $\gamma_{2}^{(n)}$ for an aged sample is decreasing with aging temperature and time, indicating the increasing contribution of the next (and higher) $n$. $n$. due to the increase in size of the clusters.

The alterations in position and line width of the $\gamma_{0}$-line were related to changes in stresses. The hydrostatic pressure, imposed on a substitutional Fe-atom in a copper crystal was estimated by using the elastic continuum approximation and a misfit parameter determined from X-ray diffraction measurements. A drop to zero of this pressure would cause a change of
$\Delta$ (I. S. $)_{\gamma_{0}}=0.018 \mathrm{~mm} / \mathrm{s}$ according to the rate of change of the (I. S.) $)_{\gamma_{0}}$ with hydrostatic pressure, which is known from high pressure Mössbauer experiments [13].

The elastic interaction energy is minimized as the oversized Fe-atoms are brought into the zero-stress positions - somewhere in the tensile stress field of a dislocation. The accommodation of the Fe-atoms to the stress field of dislocations is facilitated by the rise of several orders of magnitude in the dislocation density and their motion through the material during the process of rolling. As Fe-atoms accommodate to the non-uniform stress fields of dislocations (the density of which rises by several orders of magnitude by coldwork) a distribution of (I. S. $)_{\gamma_{0}}$ is expected-leading to a line broadening rather than to the appearance of additional resolved lines. The observed broadening - as measured directly from the spectra - was too small to provide evidence for the existence of a distribution in stress. However, a careful analysis revealed that the intrinsic broadening $\Delta \Gamma$ of the line is cancelled by a simultaneous line-narrowing due to the decrease in the sample thickness caused by rolling. The intrinsic broadening is given by : $\Delta \Gamma=\Gamma_{a}^{\mathrm{i}}-\Gamma_{a}^{\mathrm{f}}$, where $\Gamma_{a}^{\mathrm{i}}$ and $\Gamma_{a}^{\mathrm{f}}$ are the $\gamma_{0}$-line widths, before and after the cold-work respectively. This broadening was found to be approximately twice the shift of the line extrapolated to zero thickness, caused by cold-work of $87 \%$ reduction.

References

[1] NewkiRk, J. B., Trans. AIME 209 (1957) 1214.

[2] Gonser, U., Meechan, C. J., Muir, A. H. and WiedersICH, H., J. Appl. Phys. 34 (1963) 2373.

[3] Swartzendruber, L. J. and Bennetr, L. H., Phys. Lett. 27A (1968) 141.

[4] Window, B., Phil. Mag. 26 (1972) 681.

[5] Biran, A., Shoshani, A. and Montano, P. A., Nucl. Instrum. Meth. 89 (1970) 21

[6] Campbell, S. J., Clark, P. E., Liddell, P. R., J. Phys. F : Metal Phys. 2 (1972) L 114.

[7] Hornstein, F., M. Sc. Thesis (in Hebrew), TechnionI. I. T., Haifa (1974).
[8] Hornstein, F. and Ron, M.; to be published.

[9] HornsteIn, F. and Ron, M., Accepted for publication by Acta Met.

[10] Jensen, B. L., Nevald, R, and Williams, D. L., J. Phys. $F:$ Metal Phys. 2 (1972) 169.

[11] Schumacher, R. T. and Schnackenberg, G. J., Solid State Commun. 7 (1964) 1735.

[12] Beal-Monod, M. T. and Kohn, W. J., J. Phys. Chem. Solids 29 (1968) 1877.

[13] Wildiamson, D. L., Ingats, R., Phys. Lett. 34A (1971) 33. 